\title{
A Study on the Impacts of Stroke Patients Disease-Related Characteristics on Depression and Family Support.
}

\author{
Jeong-Wook Kim¹, Min-Chull Park² \\ 'Department of Physical Therapy, College of Health Sciences,Graduate School, Catholic University of Pusan; ${ }^{2}$ Department of Physical Therapy, \\ College of Health Sciences, Catholic University of Pusan Busan, Korea
}

Purpose: This study was conducted to identify the impacts of stroke patients' general and disease-related properties on depression and family support.

Methods: Subjects consisted of 79 persons who were diagnosed with cerebral hemorrhage and cerebral infarction and met the criteria for selection. The Korean version of Beck depression inventory (BDI) and a revision of the family support developed by Cobb were used. Frequency analysis of the subjects' general and medical history properties was conducted, and one way ANOVA was utilized to evaluate the degree of depression and family support with respect to the properties. Pearson's correlation coefficient was conducted to investigate the degree of depression and family support.

Results: Participants showed no significant difference in depression based on the subjects' general and disease-related properties $(p>0.05)$, although there were significant differences in family support based on marital status, hobbies and the medical expenses payers $(p<0.05)$. The correlation between family support and depression was $r=-0.491(p<0.01)$.

Conclusion: Through the results of this study, it was found that general and disease-related properties would not have any impact on depression while they would affect family support.

Keywords: Stroke, Depression, Family support

\section{서 론}

우울이란 자기에 대한 근심, 실패감, 상실감, 무가치감으로 나타나는 정서적 장애이며, ${ }^{1}$ 슬픔 감정의 정도가 오랫동안 지속되는 병적인 상 태이다. ${ }^{2}$ 우울은 일상생활 동작에도 영향을 미치는 데 중등도 이상의 우울을 가진 노인의 경우 일상생활동작에도 어려움을 겪는다. ${ }^{3}$

뇌졸중 후 환자들은 사회나 가정에서 자신의 위치에 대한 상실감 을 느끼게 되고 무력감, 당혹함, 수치심 및 자신과 주위 사람들에 대 한 분노, 짜증, 불안과 미안함 등의 감정이 복합적으로 나타나면서 우 울증으로 이환되기 쉬우며, ${ }^{4}$ 우울을 포함한 정신의학적 장애를 가지 고 있다. ${ }^{5}$ 뇌졸중 후 우울은 조기에 치료하지 않으면 7-8개월 지속될 가능성이 있으며, ${ }^{6}$ 인지 장애, 지능 장애, 감정과 감정적 행동의 분열 을 수반하여 환자에게 부정적인 영향을 끼친다. ${ }^{7}$ Angelelli 등 ${ }^{8}$ 에 의하 면 뇌졸중 후 환자들은 성급함(33\%), 불안(28\%), 무관심(27\%), 걱정 (23\%), 우울(61\%)과 같은 신경정신병적 증상을 가지고 있다. 그 중 우 울은 $61 \%$ 로 가장 높은 빈도를 차지하였다. 퇴원 후 2-5년이 지난 뇌졸
중 환자들을 대상으로 한 연구에서 $47 \%$ 가 불안 내지 우울 증상을 보 였고, ${ }^{9}$ 뇌졸중 후 환자들은 일반인에 비해 자살 사고가 $5.8 \%$ 높았으 며, 우울증상은 $2.2 \%$ 높았다. ${ }^{10}$ 또한 뇌졸중 후 환자들은 우울과 심리 사회적인 문제를 가지며, 우울로 인해 $50 \%$ 의 환자만이 손상 전 직업 으로 복귀하였다. ${ }^{11}$ 우울, 불안, 걱정과 같은 심리적 요인은 삶의 질을 낮추는 요소이며, ${ }^{12}$ 뇌졸중 환자를 대상으로 2 개월, 14 개월 후 기능상 태, 일상생활동작, 인지수행정도를 전향적으로 조사한 결과 모두 예 후에 부정적인 영향을 끼쳤다.13

사회문화적 환경 중에 우울과 연관성이 있는 것으로 가족 지지를 들 수 있다. 가족 지지란 가족 구성원들 사이에 상호의존하며, 정서적, 정신적으로 보호하는 하나의 지지체계이며, ${ }^{14}$ 환자의 삶의 질을 향상 시키는 주요한 요인의 하나이다. ${ }^{15}$ Moon 등 ${ }^{16}$ 의 연구에 의하면 뇌졸중 환자의 우울완화를 위한 연구에서 가족 지지가 클수록 생활스트레 스와 우울이 낮다고 하였다. 또한 뇌졸중 발병 3년 후 우울을 지닌 환 자를 대상으로 한 연구에서 사회적 지지가 낮을수록 우울이 높았다. ${ }^{17}$ 우울에 영향을 미치는 요인으로 노인의 경우 신문이나 잡지보기,
Received Feb 19, 2017 Revised Apr 23, 2017

Accepted Apr 27, 2017

Corresponding author Min-Chull Park

E-mail mcpark@cup.ac.kr
Copylight (C)2017 The Korea Society of Physical Therapy

This is an Open Access article distribute under the terms of the Creative Commons Attribution Non-commercial License (Http:// creativecommons.org/license/by-nc/4.o.) which permits unrestricted non-commercial use, distribution, and reproduction in any medium, provided the original work is properly cited. 
가족과 대화하기, 사회봉사 활동하기, 관광 등의 여가활동이 있다. ${ }^{18}$ 또한 가상현실에서의 댄스운동, 수중운동, 물리치료적용이 뇌졸증 환자의 우울을 감소 시켰다. ${ }^{19-21}$ 뇌졸중의 회복정도에 있어서 감정적 인 부분이 우울과 유의한 관련성이 있다. ${ }^{22} \mathrm{Park}^{23}$ 의 연구에 의하면 편 마비 환자가 경험하는 스트레스 중 신체기능 장애에서 오는 내부 스 트레스로 인해 정서적 장애인 우울을 많이 느낀다고 하였다. Lee ${ }^{24}$ 는 뇌졸중 환자의 연령, 최종 학력, 결혼상태, 치료비 부담자, 마비부위가 우울과 유의한 관련성이 있다고 하였으나, $\mathrm{Kim}^{25}$ 의 연구에 의하면 연 령, 최종 학력, 결혼상태, 치료비 부담자, 마비부위는 우울과 유의한 관련성이 없다고 하였다.

가족 지지에 영향을 미치는 요인으로 $\operatorname{Han}^{26}$ 은 결혼 상태, 치료비 부담자, 가족의 평균 수입이 가족 지지와 관련성이 있다고 하였다. 하 지만 $\mathrm{Kim}^{27}$ 의 연구에 의하면 최종 학력, 마비부위가 가족 지지와 유 의한 관련성이 있으며 결혼상태는 가족 지지와 유의한 관련성이 없 다고 하였다.

이에 본 연구는 뇌졸중 환자를 대상으로 일반적, 병력 특성 중 우 울과 가족지지에 영향을 미치는 요소를 재확인 하고, 우울과 가족 지 지와의 상관 관계를 파악하고자 한다. 또한 이러한 요소를 통해 뇌졸 증 환자를 위한 재활프로그램을 개발하는 데 필요한 기초 자료를 제 공하고자하는 데 목적이 있다.

\section{연구 방법}

\section{1. 연구대상 및 기간}

본 연구의 자료수집은 부산광역시에 위치한 2 개의 대학교병원과 4 개 종합 병원에 입원 및 외래로 방문한 뇌졸중 환자 79명을 대상으로 직 접 대면하여 시행하였다. 설문지를 배분하면서 설문지의 전반적인 내 용과 주의 사항을 전달 하였고, 문의 사항이 있거나 의문이 있을 때 연구자에게 문의 할 수 있도록 설문지 작성 완료시까지 병동내에 있 다가 직접 수거 하였다. 본 연구에 참여하는 환자의 선정기준은 다음 과 같았다. 첫째, 컴퓨터단층촬영(CT)이나 자기공명영상(MRI)에 의 하여 뇌졸중으로 진단 받았던 자. 둘째, 뇌졸중 발병 전과 뇌졸중 발 병 후에 전문의로부터 우울증으로 진단 받은 경험이 없고, 현재 항우 울제를 복용하지 않는 자. 셋째, 연구자에 의해 또는 직접 질문지를 읽 고 응답 할 수 있는 인지장애가 없는 자이다. 연구기간은 2014년 12월 1-30일까지 실시하였다.

\section{2. 실험 방법}

1) 측정 도구

(1) 우울

우울 측정 도구는 Beck의 우울척도(Beck depression inventory, BDI)를
한국인에 맞게 $\operatorname{Han}$ 등 28 이 한국어로 표준화한 한국판 $\mathrm{BDI}$ 를 사용하 였다. $\mathrm{BDI}$ 우울 척도는 우울증 평가에 널리 사용되는 평가자 간 신뢰 도 0.94의 해밀턴 우울 척도(Hamilton depression rating scale, HDRS)와 $\mathrm{r}=0.81$ 로 높은 상관관계를 보였다. ${ }^{29}$ 전체 점수척도는 0-63점이고, 0-9 점은 정상, 10-20점은 경증 우울, 21-28점은 중등도 우울, 29점 이상은 중증 우울로 판정할 수 있으며, 신뢰도 $(\mathrm{r}=0.942)$, 타당도 $(\mathrm{t}=11.39$, $\mathrm{p}<0.001)$ 이다. ${ }^{28}$

(2) 가족 지지

$\mathrm{Cobb}^{14}$ 가 개발한 가족 지지 측정 도구를 $\mathrm{Kang}^{30}$ 이 우리나라 실정에 맞게 수정, 보완한 가족 지지 측정도구를 사용하였다. 이 도구는 5점 척도 11 문항으로 구성되어 있고, 최저 점수 11 점에서 최고 55 점까지이 다. 점수가 높을수록 가족 지지 정도가 높음을 의미한다. 도구의 개 발당시 신뢰도는 Cronbach's alpha 값이 0.86 이었고, $\mathrm{Kang}^{30}$ 의 연구에 서는 0.90 이었다.

\section{3. 통계분석 및 자료처리}

수집된 자료는 SPSS version 12.0을 이용하여 통계처리 하였다. 대상자 의 일반적 특성, 질병관련 특성에 대해 확인하기 위하여 빈도 분석을 실시하였다. 대상자의 우울, 가족 지지정도는 기술통계 분석을 실시 하였다. 또한 대상자의 일반적 특성, 질병관련 특성에 따른 우울 정 도, 가족 지지를 확인하기 위하여 독립표본 T 검정(independent t-test) 와 일원변량분석(one-way ANOVA)을 실시하였다. 사후검정을 위해 서 Duncan test를 실시하였으며, 우울정도와 가족 지지의 연관성을 파악하기 위해 Pearson's correlation을 시행 하였다. 통계적 유의 수준 은 0.05 이하로 하였다.

\section{결 과}

\section{1. 대상자의 특성}

\section{1) 일반적 특성}

연구 대상자 전체 79명 중 성별은 남성 45명(57.0\%)여성 34명(43.0\%)이 었고, 연령은 평균 58.24세이었으며 연령의 분포는 30 대 4 명(5.1\%), 40 대 12명(15.2\%), 50대 30명(38.0\%), 60대 18명(22.8\%), 70대 15명(19.0\%)이 었다. 학력은 무학 6 명(7.6\%), 초등학교 졸업 12 명(15.2\%), 중학교 졸업 15 명(19.0\%), 고등학교 졸업 33명(41.8\%), 대학교 졸업 13명(16.5\%)이었으 며, 종교를 가진 대상자는 52명(65.8\%), 종교를 가지지 않은 대상자는 27 명(34.2\%)이었다. 결혼 상태는 유배우자 46명(58.2\%), 사별 13명 (16.5\%), 별거 또는 이혼 8 명(10.1\%), 미혼 12 명(15.2\%)이었다. 취미를 가 진 대상자는 25명(31.6\%)이었고, 취미를 가지지 않은 대상자는 54명 (68.4\%)이었다. 언어장애가 있는 대상자는 28명(35.4\%)이었고, 언어장 
애가 없는 환자는 51 명(64.6\%)이었으며, 보행이 가능한 대상자 55 명 (69.6\%)이었고, 보행이 불가능한 대상자 24 명 $(30.4 \%)$ 이었다. 기억력 장 애가 있는 대상자 25 명 $(31.6 \%)$ 이었고, 기억력 장애가 없는 대상자 54 명 $(68.4 \%)$ 이었다.

\section{2) 대상자의 질병관련 특성}

연구 대상자 전체 79 명 중 뇌출혈인 경우 30 명(38.0\%), 뇌경색인 경우
47명(59.5\%), 뇌경색과 뇌출혈 복합인 경우 2 명 $2.5 \%)$ 이었다. 마비 부위 는 오른쪽 반신마비 42 명(53.2\%). 왼쪽 반신마비 27명(34.2\%), 양측마 비 10명(12.7\%)이었다.

\section{3) 대상자의 가족관련 특성}

연구 대상자 전체 79명 중 치료비 부담자가 부모인 경우 4 명 $(5.1 \%)$, 본 인(또는 배우자)인 경우 29명(36.7\%), 자녀인 경우 20명(25.3\%), 형제인

Table 1. Levels of depression according to the general characteristics of the subject $(n=79)$

\begin{tabular}{|c|c|c|c|c|}
\hline Characteristic & Sortation & Average (standard deviation) & t/F-value & $\mathrm{p}$ \\
\hline \multirow[t]{2}{*}{ Gender } & Men & $15.60(10.463)$ & -1.595 & 0.115 \\
\hline & Women & $19.50(11.153)$ & & \\
\hline \multirow[t]{5}{*}{ Age } & Thirty & $12.00(6.218)$ & 1.197 & 0.320 \\
\hline & Forty & $17.67(11.703)$ & & \\
\hline & Fifty & $19.00(11.289)$ & & \\
\hline & Sixty & $19.06(12.785)$ & & \\
\hline & Seventy & $12.80(6.316)$ & & \\
\hline \multirow[t]{5}{*}{ Academic background } & Lack of schooling & $19.83(11.462)$ & 0.306 & 0.873 \\
\hline & Graduated primary school & $16.42(12.486)$ & & \\
\hline & Graduated middle school & $18.67(11.425)$ & & \\
\hline & Graduated high school & $17.42(9.785)$ & & \\
\hline & Graduate college & $14.92(12.257)$ & & \\
\hline \multirow[t]{4}{*}{ Marital status } & Spouse exist & $17.52(9.941)$ & 0.291 & 0.832 \\
\hline & Bereavement & $15.15(8.040)$ & & \\
\hline & Divorce & $19.63(19.346)$ & & \\
\hline & Single & $17.08(10.732)$ & & \\
\hline \multirow[t]{2}{*}{ Religion } & Exist & $18.23(10.392)$ & 1.082 & 0.283 \\
\hline & No exist & $15.44(11.719)$ & & \\
\hline \multirow[t]{2}{*}{ Hobby } & Exist & $14.76(10.453)$ & -1.410 & 0.163 \\
\hline & No exist & $18.44(10.956)$ & & \\
\hline \multirow[t]{2}{*}{ Language disorder } & Exist & $18.07(11.966)$ & 0.478 & 0.634 \\
\hline & No exist & $16.84(10.318)$ & & \\
\hline \multirow[t]{2}{*}{ Gait } & Possible & $19.57(10.486)$ & -1.739 & 0.091 \\
\hline & Impossible & $20.17(13.205)$ & & \\
\hline \multirow[t]{2}{*}{ Memory disorder } & Exist & $16.92(9.912)$ & -0.198 & 0.843 \\
\hline & No exist & $17.44(11.371)$ & & \\
\hline \multirow[t]{3}{*}{ Paralysis region } & Right hemiparalysis & $17.12(10.419)$ & 0.114 & 0.892 \\
\hline & Left hemiparalysis & $17.96(10.872)$ & & \\
\hline & Paraplegia & $16.10(13.601)$ & & \\
\hline \multirow[t]{5}{*}{ Medical expenses burden } & Parents & $15.25(7.500)$ & 0.637 & 0.638 \\
\hline & Myself (or spouse) & $18.55(12.333)$ & & \\
\hline & Descendant & $15.70(9.498)$ & & \\
\hline & Brother & $11.80(12.438)$ & & \\
\hline & A public institution & $18.71(10.364)$ & & \\
\hline \multirow[t]{4}{*}{ Monthly average income (unit: million won) } & Less than 200 & $19.64(11.930)$ & 2.455 & 0.070 \\
\hline & $200-300$ & $11.80(6.971)$ & & \\
\hline & $300-400$ & $15.00(6.992)$ & & \\
\hline & More than 400 & $14.00(9.967)$ & & \\
\hline
\end{tabular}

${ }^{*} p<0.05,{ }^{* *} p<0.01$. 
경우 5 명(6.3\%), 공공기관인 경우 21 명(26.6\%)였다. 가족의 한달 평균 수입은 200만 원 미만인 경우 50명(63.3\%), 200-300만 원 미만인 경우 15 명(19.0\%),300-400만 원 미만인 경우 10 명(12.7\%), 400만 원 이상인 경우 4 명(5.1\%)이었다.

\section{2. 대상자의 우울, 가족 지지와 일상생활동작의 정도}

총 우울은 총점 63 점이며 최소 1점에서 최대 50 점까지 분포 하였고, 평균 17.28점 $( \pm 8.223)$ 으로 나타났으며, 비신체적 우울이 9.76점, 신체
적 우울이 7.52점으로 나타났다. 가족 지지는 55점 만점에 최소 11 점 에서 최대 48 점까지 분포 하였고, 총 가족 지지의 평균은 $37.48( \pm$ 8.223 )이었다. 가족 지지의 하부 영역에서는 정서적 지지 14.25 점, 정보 적 지지 7.29점, 물질적 지지 8.70점, 평가적 지지 7.24점으로 나타났다.

대상자들의 우울 정도는 총 79명의 대상자 중 9점 이하의 정상군 이 22명(22.8\%), 경증 우울군이 28명(35.4\%), 중등도 우울군이 13 명 (16.4\%), 중증 우울군이 16 명(20.4\%)이었다.

Table 2. Degree of family support dependent on disease related characteristics $(n=79)$

\begin{tabular}{|c|c|c|c|c|}
\hline Characteristic & Sortation & Average (standard deviation) & t/F-value & $\mathrm{p}$ \\
\hline \multirow[t]{2}{*}{ Gender } & Men & $38.20(8.187)$ & 0.893 & 0.375 \\
\hline & Women & $36.53(8.295)$ & & \\
\hline \multirow[t]{5}{*}{ Age } & Thirty & $39.00(6.683)$ & 0.300 & 0.877 \\
\hline & Forty & $35.25(9.855)$ & & \\
\hline & Fifty & $37.57(8.585)$ & & \\
\hline & Sixty & $38.39(9.262)$ & & \\
\hline & Seventy & $37.60(5.289)$ & & \\
\hline \multirow[t]{5}{*}{ Academic background } & Lack of schooling & $34.67(5.538)$ & 0.250 & 0.909 \\
\hline & Graduated primary school & $37.50(9.644)$ & & \\
\hline & Graduated middle school & $36.80(10.129)$ & & \\
\hline & Graduated high school & $38.03(7.896)$ & & \\
\hline & Graduate college & $38.15(7.046)$ & & \\
\hline \multirow[t]{4}{*}{ Marital status } & Spouse exist & $39.35(5.820)$ & 3.616 & 0.017 \\
\hline & Bereavement & $38.00(5.802)$ & & \\
\hline & Divorce & $30.50(12.570)$ & & \\
\hline & Single & $34.42(11.958)$ & & \\
\hline \multirow[t]{2}{*}{ Religion } & Exist & $38.60(7.484)$ & 1.693 & 0.095 \\
\hline & No exist & $35.33(9.257)$ & & \\
\hline \multirow[t]{2}{*}{ Hobby } & Exist & $40.68(7.739)$ & 2.425 & 0.018 \\
\hline & No exist & $36.00(8.082)$ & & \\
\hline \multirow[t]{2}{*}{ Language disorder } & Exist & $38.61(7.269)$ & 0.901 & 0.370 \\
\hline & No exist & $36.86(8.709)$ & & \\
\hline \multirow[t]{2}{*}{ Gait } & Possible & $37.49(7.703)$ & 0.016 & 0.987 \\
\hline & Impossible & $37.46(9.487)$ & & \\
\hline \multirow[t]{2}{*}{ Memory disorder } & Exist & $37.64(8.175)$ & 0.116 & 0.908 \\
\hline & No exist & $37.41(8.320)$ & & \\
\hline \multirow[t]{3}{*}{ Paralysis region } & Right hemiparalysis & $37.19(8.577)$ & 1.227 & 0.299 \\
\hline & Left hemiparalysis & $36.56(8.396)$ & & \\
\hline & Paraplegia & $41.20(5.371)$ & & \\
\hline \multirow[t]{5}{*}{ Medical expenses burden } & Parents & $26.25(14.728)$ & 2.526 & 0.048 \\
\hline & Myself (or spouse) & $38.90(8.050)$ & & \\
\hline & Descendant & $36.55(6.621)$ & & \\
\hline & Brother & $36.00(8.337)$ & & \\
\hline & A public institution & $38.90(7.293)$ & & \\
\hline \multirow[t]{4}{*}{ Monthly average income (unit: million won) } & Less than 200 & $37.02(7.878)$ & 1.766 & 0.161 \\
\hline & $200-300$ & $40.53(7.981)$ & & \\
\hline & $300-400$ & $38.00(10.392)$ & & \\
\hline & More than 400 & $30.50(2.646)$ & & \\
\hline
\end{tabular}

${ }^{*} p<0.05,{ }^{* *} p<0.01$. 
Table 3. The correlation between depression and family support $(n=79)$

\begin{tabular}{lc}
\hline & Family support \\
\hline Depression & $-0.491^{* *}$ \\
\hline${ }^{*} \mathrm{p}<0.05,{ }^{* *} \mathrm{p}<0.01$ &
\end{tabular}

\section{3. 대상자의 특성에 따른 우울정도}

대상자의 특성에 따른 우울정도는 유의한 차이가 없었다 $(\mathrm{p}>0.05)$ (Table 1).

\section{4. 대상자의 특성에 따른 가족 지지정도}

결혼상태에 따른 가족 지지 정도는 유의미하게 차이가 나타났다 $(\mathrm{F}=3.616, \mathrm{p}=0.017)(\mathrm{p}<0.05)$. 이를 Duncan 사후검정을 한 결과 유배우 자와 사별인 경우가 별거 또는 이혼보다 가족 지지가 높았다. 취미의 유무에 따른 가족 지지의 정도도 통계적으로 유의미한 차이를 보였 고 $(\mathrm{F}=2.425, \mathrm{p}=0.018)$, 취미가 있는 경우(40.68점)가 취미가 없는 경우 (35.33점)보다 가족 지지가 높은 것으로 나타났다 $(\mathrm{p}<0.05)$. 치료비 부 담자에 따라 가족 지지정도가 유의미하게 차이를 보였고 $(\mathrm{F}=2.526$, $\mathrm{p}=0.048)(\mathrm{p}<0.05)$, 이를 Duncan 사후검정 한 결과 치료비 부담자가 본인(또는 배우자), 공공기관인 경우가 치료비 부담자가 부모인 경우 보다 가족 지지정도가 높은 것으로 나타났다(Table 2).

\section{5. 우울, 가족 지지 상관관계}

우울 정도와 가족 지지의 상관관계를 살펴보면 가족 지지와 우울과 는 $r=-0.491(\mathrm{p}<0.01)$ 의 유의한 역 상관관계를 보였다. 즉 가족 지지가 높을수록 우울정도가 낮아짐을 확인할수 있었다(Table 3).

\section{고 찰}

뇌졸중 환자들은 신체적 기능점수와 삶의 질의 점수가 낮다. ${ }^{31}$ 또한 신체적 장애뿐만 아니라 불안, 우울, 흥분과 같은 정서적 장애를 가지 고 있다. ${ }^{32}$ 이 중 우울은 발병 후 긴 시간 지속되는 휴유증이다.33

선행 논문에 의하면 뇌졸중 환자의 $22.9 \%$ 가 경증 우울증이 있고, $22.9 \%$ 는 중간 정도의 우울증이 있으며 $11.4 \%$ 가 심한 우울증이 있는 것으로 나타나 전체의 $57.1 \%$ 가 우울증 증상이 있는 것으로 나타났 다. ${ }^{34}$ 본 연구에서 우울 빈도는 정상으로 판단된 대상자가 $27.8 \%(22$ 명), 경증 우울이 $35.4 \%$ (28명), 중등도 우울이 $20.4 \%$ (16명), 심한 우울 증이 $20.4 \%$ (16명)으로 나타나 전체의 $72.2 \%$ (67명)가 우울 증상이 있 는 것으로 나타났다. You ${ }^{35}$ 는 평가 방법에 따라 우울증 발생률이 달 라 질 수 있다고 하였는 데, 자기보고식 평가방법인 경우 환자의 주관 적인 보고에 전적으로 의존하여 관찰자 평가 척도보다 우울증 발생 률이 높아 질 수 있다고 하였다. 본 연구 평가 도구인 BDI는 자기보고
식 평가방법으로 선행연구보다 높은 발생률이 나타난 것으로 생각된 다. 또한 뇌졸중 후 각기 다른 시기에 있는 환자를 대상으로 하여 대 표성에 제한이 있기 때문에 연구결과의 차이를 보인 것으로 여겨진 다. ${ }^{36}$

뇌졸중 후 편마비 환자의 성별에 따른 우울에 관한 연구는 서로 상 반되는 결과가 보고되었다. $\mathrm{Kim}^{25}$ 과 $\mathrm{Lee}^{24}$ 는 성별과 우울은 유의한 관련성이 없다고 하였다. 그러나 Paradiso와 Robinson, ${ }^{37}$ Schultz 등 ${ }^{38}$ 은 성별과 우울은 유의한 관련성이 있다고 하였다. 본 연구에서는 성별 과 우울은 유의한 관련성이 없었다. 이러한 이유로 우울은 선천적인 요인보다 사회적 역할과 같은 후천적인 요인에 영향을 받으며, 사회적 으로 남성과 여성의 역할이 분리되지 않는 등 사회적 지지, 배경에 큰 차이가 없기 때문이라고 사료된다.

마비 부위에 따른 우울에 관한 연구에서 마비부위와 우울은 유의 한 관련성이 있었다. ${ }^{24,38}$ 그러나 $\mathrm{Kim},{ }^{25} \mathrm{Han},{ }^{28}$ Angeleri 등 ${ }^{17}$ 의 연구에 의하면 마비 부위와 우울은 유의한 관련성이 없었다. 본 연구에서도 마비부위와 우울은 유의한 관련성이 없었다. 이러한 이유는 우울과 관련이 있는 세로토닌과 같은 신경전달물질경로의 문제로 우측 편마 비 환자에게 우울의 발생이 온다고 하였으나. ${ }^{39}$ 발병 후 6개월이 지난 환자는 생리학적 요인보다 심리사회적인 요인이 우울에 영향을 끼친 다고 하였다. ${ }^{40}$ 본 연구에서도 연구 대상자가 6 개월이 지난 만성 뇌졸 중 환자였기 때문에 생리학적 요인보다 심리사회적인 요인의 영향을 받아 우울과 유의한 관련성이 없는 것으로 나타났다고 사료된다.

최종학력이 우울에 미치는 영향은 상반된 결과를 보인다. Lee, ${ }^{24}$ $\operatorname{Han}^{26}$ 은 최종학력이 낮을수록 우울의 발생이 높다고 하였다. 그러나 $\mathrm{Kim},{ }^{25} \mathrm{Moon},{ }^{38}$ Angeleri 등 ${ }^{17}$ 은 최종 학력은 우울에 영향을 주지 못한 다고 하였다. 본 연구에서는 우울과 최종 학력은 유의한 관련성이 없 었다. 또한 결혼 상태에 따른 우울에 관한 연구에서 결혼 상태는 우 울과 유의한 관련성이 없었다.

본 연구에서 뇌졸중 후 편마비 환자의 결혼 상태에 따른 가족 지지 정도는 유의한 관련성이 있었다. $\mathrm{Moon}^{38}$ 와 $\operatorname{Han}^{26}$ 의 연구에 의하면 결 혼 상태에 따른 가족 지지 정도는 유의한 관련성이 있었고, 결혼하여 배우자가 있는 경우에 가족 지지가 높다는 본 연구의 결과와 일치하 였다. 이러한 이유는 가족 중 배우자가 환자에게 지지 역할을 많이 하 고 있고, 별거 또는 이혼 한 경우보다 가족관계가 돈독하여 가족 지 지를 많이 받고 있다고 사료된다. 본 연구에서 취미의 유무는 가족 지 지와 유의한 관련성이 있었는데 이는 환자가 취미를 가지고 있는 만 큼 적극적인 생활을 하고 있으므로 가족은 무관심보다 관심을 가지 게 되어 환자는 높은 가족 지지를 받고 있다고 사료된다.

본 연구에서 치료비 부담자가 본인(또는 배우자), 공공기관인 경우 가 부모인 경우보다 가족 지지정도가 높다고 하여 $\operatorname{Park}^{41}$ 의 연구 결과 와 일치 하였다. 이는 형제와 자녀가 치료비 부담을 들 수 있어 환자에 
대한 지지가 높을수 있다고 사료된다.

뇌졸중 환자의 가족 지지와 우울과의 상관관계에서 $\operatorname{Han}^{26}$ 은 가족 지지와 우울이 유의한 상관관계가 있다고 하였다. 뇌졸증 환자에 있 어서 가족지지는 사회적지지 개념의 한 부분으로 환자가 감정적인 대화를 할 수 있도록 지지하고, ${ }^{42}$ 우울, 불안, 무기력감을 감소시키는 역할을 한다고 하였다. ${ }^{33}$ 이에 본 연구에서도 가족 지지와 우울은 유 의 수준 0.01 하에서 통계적으로 유의하게 가족 지지 정도가 높을수 록 우울의 정도가 낮은 것으로 나타났다.

본 연구의 제한점으로는 첫째, 대상자들은 부산지역에 소재하는 입원, 외래 치료를 받는 대상자들이기 때문에 타지역의 대상자들에 게 일반화하기에는 제한이 따른다는 점이다. 둘째, 본 연구의 참여대 상자들이 의사소통이 가능하거나 읽고 쓰는데 문제가 없는 뇌졸중 의 정도가 경한 환자들이었다. 이는 뇌졸중의 정도가 심한 환자 모두 에게 일반화시키기에는 무리가 따를 것으로 생각된다.

본 연구는 뇌졸증 환자의 일반적 특성이 가족지지와 우울에 미치 는 영향을 알아보고 가족지지와 우울과의 관련성을 알아보고자 시 행되었다. 그 결과 79 명 중 경증 우울군이 28 명 $(22.8 \%)$, 중등도 우울군 이 13 명(16.4\%), 심한우울군이 16 명(20.4\%)이었다. 대상자의 특성에 따 른 우울 정도는 유의한 차이가 없었으며, 결혼상태, 취미의 유무, 치료 비 부담자에 따라 가족지지 정도는 유의한 차이가 있었다. 또한 가족 지지가 높을수록 우울정도가 낮아졌다. 이러한 연구 결과를 통해서 뇌졸중 후 편마비 환자들의 가족 지지와 우울의 관계를 이해하고 가 족 지지에 영향을 미치는 일반적 병력 특성을 파악하여, 가족의 지지 를 높일 수 있는 중재가 필요하다고 사료된다. 또한 뇌졸중 환자의 재 활 프로그램을 구성하는 데 참고자료로 이용되었으면 한다.

\section{참고문헌}

1. Beck AT, Ward CH, Menderson M et al. An inventory measuring depression. Arch Gen Psychiatry. 1961;4:561-71.

2. Han DS. Psychiatry. Seoul, Ilchokak, 1972.

3. Jung SM, Park LJ, No HR. Correlation of depession and activity of daily living in the elderly. J Kor Phys Ther. 2010;22(2):31-8.

4. Lee JA, Lee JH, Lim SM et al. Correlation between post stroke depression and activities of daily living. J of Oriental Neuropsychiatry. 2000;11(2): $149-54$.

5. Fukunish I. Aoki T, Hosaka T. Correlations for social support with depression in the chronic post stroke period. Percept Mot Skills. 1997; 85:811-8.

6. Tiller JWG. Post stroke depression. Psychopharmacology (Berl). 1992;106:S130-3.

7. Andersen G. Post-stroke depression: diagnosis and incidence. Eur Psychiatry. 1997;12(Suppl3): 255-60.

8. Angelelli P, Paolucci S, Bivona U et al. L. Development of neuropsychiatric symptoms in post stroke patients: a cross-sectional study. Acta Psy- chiatr Scand. 2004;110(1):55-63.

9. Bergersen H, Frøslie KF, Stibrant Sunnerhagen K et al. Anxiety, depression, and psychological well-being 2 to 5 years poststroke. J Stroke Cerebrovasc Dis. 2010;19(5):364-9.

10. Fuller-Thomson E, Tulipano MJ, Song M. The association between depression, suicidal ideation, and stroke in a population-based sample. Int J Stroke. 2012;7(3):188-94.

11. Neau JP, Ingrand P, Mouille-Brachet C et al. Functional recovery and social outcome after cerebral infarction in young adults. Cerebrovasc Dis. 1998;8(5):296-302.

12. Kang SK, Kim SK, Hwang SK. Quality of life of the normal old people and those with the stroke quality of life of the normal old people and those with the stroke. J Spec Educ Rehab. 2008;41(1):47-59.

13. Morris PL, Raphael B, Robinson RG. Clinical depression is associated with impaired recovery from stroke. Med J Aust. 1992;157(4):239-42.

14. Cobb S. Social support as a moderator as life stress. Psychosom Med. 1976;38(5):300-14.

15. Park IH, Park SW, Kwon HC. The Correlation between quality of life and family support of stroke patients. Society of Occupational Therapy for the Agged and Dementia. 2011;5(2);41-9.

16. Moon SK, Jung JE, Son ES. Analysis of the mediating effects of family support and social participation between daily hassles and depression for the elderly with stroke disabilities. Korean Journal of Family Social Work. 2008;24:223-48.

17. Angeleri F, Angeleri VA, Foschi N, Depression after stroke : an investigation through catamnesis J Clin Psychiatry. 1997;58(6):261-5.

18. Kwon WA, Kim HS. A Study on the correlation between the types of leisure activity and depression in the elderl-in Bukgu district, Daegu city. J Kor Soc Phys Ther. 2008;20(4):51-9.

19. Lee SJ, Jung SY. Change of depression according to physical therapy in stroke patients. J Kor Soc Phys Ther. 2001;13(1): 33-40.

20. Kim ym, Lee dk. Effects of dance sports in virtual reality on balance, depression and ADL in stroke patients. J Kor Soc Phys Ther. 2013;25(5): 360-5.

21. Kim SH, Lee DK, Kim EK. Effect of aquatic exercise on balance and depression of stroke patients. J Kor Soc Phys Ther. 2014;26(2):104-9.

22 Ha MS, Park MC, Goo BO. The effect of recovery of disability on poststroke depression. J Korean Soc Phys Med. 2010;5(4):623-32.

23. Park K. Perceive stress and depression in hemiplegia patients using neuman stressors concepts factors. Ewha Womans Universty. Dissertation of Master's Degree. 1988.

24. Lee MH. Influencing factors of depression and stress in stroke patients. Gosin Universty. Dissertation of Master's Degree. 2009.

25. Kim HS. The impacts of stroke patients' depression, motivation for rehabilitation and activities of daily living on quality of life. Hanyang Universty. Dissertation of Master's Degree. 2009.

26. Han YA. Analysis of in daily activities, family support and depression in hemiparesis patients due to stroke. Yonsei Universty. Dissertation of Master's Degree. 2004.

27. Kim HS. Study on quality of life, self-efficacy an family support of stroke patients in oriental medicine hospitals. Dong eui Universty. Dissertation of Master's Degree. 2003.

28. Hwan HM, Yum TM, Sin YW et al. A clinical of depressive trends in medically ill patients with the Beck depression inventory. J Korean Neu- 
ropsychiatr Assoc. 1986;25(3):487-500.

29. Lee DJ, Sim JK, An SH. A comparison of different depression instruments for stroke patients. J Kor Phys Ther. 2011;23(2):69-76.

30. Kang HS. Experimental study of the effects of reinforcement education for rehabilitation on hemiplegia patients' self-care activities. Yonsei Universty. Dissertation of Doctorate Degree. 1984.

31. Kwon JM. Daily physical functioning and quality of life for stroke. J Kor Phys Ther. 2007;19(5):87-96.

32. Olsen TS. Arm and leg paresis as outcome predictors in stroke rehabilitation. Stroke. 1990;21(2):247-51.

33. Francesco C, Silvana G. Depression and cerebral stroke. J Clin Psychiatry. 1990;51(9):9-12.

34. Lee DJ, Ko TS. Relationships between symptoms of depression and cognitive function, physical functions, and activities of daily living in stroke patients. J Spec Educ Rehab. 2010;49(4):159-78.

35. Yoo SD. The Relationship between minimental status examination and computerized cognitive impairment poststroke depression Kwandong Med J. 2003;7(2):17-24.

36. Park JH. A study on the impacts of stroke patients depression and the sexual satisfaction of daily living on quality of life. Kyung Hee Universty.
Dissertation of Master's Degree. 2011.

37. Paradiso S, Robinson RG. Gender differences in post stroke depression. J Neuropsychiatry Clin Neurosci. 1998;10(1):41-7.

38. Moon HH. Relationship among depression, family support, and rehabilitation motive in patient with acute or subacute hemorrhagic. Yonsei Universty. Dissertation of Master's Degree. 2010.

39. Parikh RM, Lipsey JR, Robinson RG et al. A two year longitudinal study of poststroke mood disorders: progmostic factors related to one and two year outcome. Int J Psychiatry Med. 1988; 18(1):45-6.

40. Kim JM, Sin HY. Diagnosis and treatment of poststroke depression. J Korean Soc Biol Psychiatry. 2005;12(2):89-97.

41. Park YR. A study of burden in family caregivers and perceived family support in patient with stroke. Kyung Hee Universty. Dissertation of Master's Degree. 2000.

42. Lidell E. Family support- a burden to patient and caregiver. Eur J Cardiovasc Nurs. 2002;1(2):149-52.

43. Okkonen E, Vanhanen H. Family support, living alone and subjective health of a patient in connection with a coronary artery bypass surgery. Heart Lung. 2006;35(4):234-44. 